\title{
El tratamiento de los elementos de formación de palabras denominados prefijos en diccionarios generales
}

\author{
MARÍA TADEA DÍAZ HORMIGO \\ Universidad de Cádiz
}

1. Aunque existe un amplio consenso cuando se trata de determinar que las unidades lingüísticas que deben ser objeto de tratamiento lexicográfico en los diccionarios generales han de ser únicamente las unidades léxicas, suele ser práctica habitual la inclusión como artículos independientes, en la macroestructura de estos diccionarios, tanto de las denominadas palabras gramaticales como de los elementos que intervienen en la formación de palabras (fundamentalmente, prefijos, sufijos y raíces cultas de origen griego o latino), esgrimiéndose como razones para justificar el hecho de que se consignen estos elementos formativos, sobre todo, la economía de espacio y la imposibilidad de registrar como entradas del diccionario todos los resultados pertinentes de la formación productiva de palabras.

Pero no trataremos en este artículo sobre la conveniencia o la adecuación de la inclusión de tales elementos formativos en el inventario o repertorio lexicográfico, sino que lo que pretendemos es mostrar el tratamiento que han recibido estos elementos productivos de formación de palabras en diccionarios generales desde la aparición y consolidación del modelo académico en los siglos XVIII y XIX hasta nuestros días, atendiendo para ello tanto a la información que sobre tales elementos se nos ofrece en los correspondientes artículos lexicográficos como a las referencias que respecto a su incorporación y registro se hacen en las partes introductorias de estos diccionarios. No obstante, por razones de espacio, centraremos nuestro interés en los elementos formativos que, en la terminología actual, se denominan comúnmente prefijos, respecto a los cuales, por una parte, pretendemos determinar si los objetivos que a propósito de estas formas trabadas se exponen en las partes introductorias de los correspondientes diccionarios se cumplen realmente en el cuerpo del diccionario y la manera de llevar a la práctica tales objetivos en la confección del correspondiente artículo lexicográfico; por otra parte, procuraremos establecer las analogías y, sobre todo, las diferencias que se observan al cotejar las informaciones que, sobre estas unidades lingüísticas, se ofrecen en los diferentes repertorios lexicográficos y en las distintas ediciones de un mismo diccionario, $\mathrm{y}$, por último, intentaremos comprobar si el tantas veces denunciado hiato o divorcio entre gramática y diccionario se observa también en el tratamiento lexicográfico que se da a estos elementos formativos.

Asimismo, con el objeto de enmarcar el tema propuesto en la perspectiva evolutiva que hemos adoptado, consideraremos, en la que, desde el punto de vista de su estructura, puede ser considerada la primera parte de nuestro artículo, que comprende los apartados 2., 3. y 4., los diccionarios usuales de la lengua española editados por la Real Academia Española — por tanto, el período que se inicia en 1780 con la publicación de 
la primera edición del Diccionario de la lengua castellana y termina en 2003 con la elaboración de la versión electrónica del texto correspondiente a la segunda tirada corregida de la, hasta el momento, última edición (la vigésima segunda) del Diccionario de la lengua española -.$^{1}$ En este sentido, resulta necesario precisar que para la conformación del corpus que será objeto de nuestra indagación procedimos a la selección de los formantes catalogados como prefijos en las letras A e I de esta última edición del diccionario académico, así como de los que han resultado del cotejo de estas entradas con las correspondientes que figuran consignadas en las anteriores ediciones del diccionario usual de la lengua española de la Real Academia Española. ${ }^{2}$ Los resultados obtenidos del análisis de los aspectos concretos que nos ocupan en estas unidades registradas en las letras A e I de estos diccionarios serán contrastados, en la segunda parte de nuestro artículo, que abarca el apartado 5., con los que arroje nuestra revisión del tratamiento que han recibido estos elementos de formación de palabras en muestras representativas de la lexicografía no académica, entre las que hemos seleccionado, por su especial singularidad, al menos en lo que se refiere a la materia que es objeto de nuestro interés, el Diccionario de uso del español de M. Moliner, el Clave. Diccionario de uso del español actual, dirigido por C. Maldonado González, y el Diccionario del español actual de M. Seco, O. Andrés y G. Ramos. En el apartado 6. exponemos las conclusiones a las que hemos llegado tras nuestro tratamiento del tema.

2. Pues bien, es en el «Prólogo» de la sexta edición del Diccionario de la lengua castellana, del año 1822, donde por primera vez la Real Academia Española hace una referencia explícita a uno de los elementos que actualmente denominamos prefijos, ya que, entre las voces que, según se indica, se suprimen del cuerpo del diccionario, se encuentran «muchas corrompidas por resabios de la primera educación, como las que por $r$ tienen $n$ en los compuestos de la preposición in, por ejemplo, inremediable, inresistible, inreparable». Y, aunque también en el «Prólogo» de la siguiente edición del diccionario académico, la séptima (cf. Real Academia Española, 1832), se menciona que se continúa con la supresión de estos vocablos «que solo por viciosa pronunciación se diferencian en algo de los propios y castizos», no se encuentra en la parte introductoria de ésta ni de ninguna otra edición de los diccionarios académicos alusión alguna a los elementos formativos que aquí tratamos hasta la que figura en el «Preámbulo» de la vigésima primera edición del Diccionario de la lengua española, de 1992, en el que se afirma que «las etimologías de palabras derivadas o compuestas se han simplificado mediante la presencia y definición de sufijos, prefijos y elementos compositivos en el cuerpo del DICCIONARIO», práctica esta que se mantiene en la hasta por el momento última edición de este diccionario (cf. Real Academia Española, 2003), en cuyo aparta-

${ }^{1}$ Aunque en cada caso remitiremos a las correspondientes ediciones del diccionario usual de la lengua castellana (1. a $14 .{ }^{a}$ ed.) o española (desde la 15. ${ }^{\mathrm{a}}$ ed.) de la Real Academia Española, para la consulta de las ediciones 1. ${ }^{\mathrm{a}}$ a $11 .^{\mathrm{a}}$ nos hemos basado en Real Academia Española (2001). este trabajo.

${ }_{2}^{2}$ Para la relación de las unidades analizadas que conforman nuestro corpus, véase el Apéndice de 
do de «Advertencias para el uso de este Diccionario» se especifica que los elementos compositivos, prefijos y sufijos «se incluyen en el Diccionario, por regla general, cuando manifiestan capacidad productiva en la lengua actual. Aparecen en el lugar que les corresponde alfabéticamente, pospuestos a los otros tipos de palabras cuando coinciden en su forma. Así, a se sitúa antes que a-, y ario, ria antes que -ario, ria».

No obstante, en cualquier caso, desde que en 1780 la Real Academia compendió los seis volúmenes del Diccionario de Autoridades en uno solo para facilitar su manejo y consulta, empezó a hacer uso de una serie de recursos para hacer factible esa reducción, los cuales, aunque ninguno de ellos es propuesto específicamente para confeccionar la microestructura de las entradas de los elementos de los que aquí nos ocupamos sino la de todos los lemas consignados en el cuerpo del diccionario, deben ser examinados en relación con la información contenida en los artículos correspondientes a las unidades que constituyen nuestro corpus, ya que este cotejo de las pautas que, en las partes introductorias, se dice que se van a seguir y la manera de proceder a la hora de exponer las informaciones en los artículos lexicográficos puede arrojar datos relevantes en lo que se refiere al tratamiento de las unidades morfológicas en los diccionarios generales.

En efecto, ya en el «Prólogo» de la primera edición del diccionario usual de la Real Academia (cf. Real Academia Española, 1780), se advierte de la utilización de abreviaturas, así como de la no inclusión de la etimología de las voces, de tal manera que, según se pretende, en la microestructura del diccionario, quedaría consignada sólo la voz, la definición y la correspondencia latina. Ahora bien, la consulta de los artículos lexicográficos de las unidades de nuestro corpus registradas en esta primera edición del diccionario académico (en concreto, los de los lemas A. e IN.) nos permite comprobar que, efectivamente, se ha indicado la correspondencia latina de estas unidades, pero, sin embargo, no siempre se hace uso de una abreviatura para indicar su categoría lingüística, a pesar de ser ésta la misma para estos lemas -la de preposición- y de que la abreviatura había sido incluida y explicada en las páginas preliminares de la parte introductoria del diccionario reservadas a tal efecto. Asimismo, pese a lo que se indica sobre consignar sólo la voz, la definición y la correspondencia latina, en los correspondientes artículos lexicográficos se incluyen indicaciones relativas a la utilización de estas unidades en la composición de palabras, información esta de carácter funcional o teleológico que a veces suple a la propia definición o información de contenido semántico.

Estas mismas incoherencias entre los propósitos que se formulan en las páginas del «Prólogo» de la primera edición del diccionario académico y las pautas que se siguen en la confección de los artículos lexicográficos se mantienen, casi en su totalidad, en las sucesivas ediciones del diccionario de la lengua castellana hasta su undécima edición inclusive, la del año 1869, siendo relevante el hecho de que, además, desde la cuarta hasta de nuevo en la duodécima edición, no se emplean abreviaturas para la indicación de la categoría lingüística de las unidades de nuestro corpus que aparecen consignadas. Asimismo, en lo referente a la anotación de la correspondencia latina, se observa que para la unidad lexicográfica ANTI., registrada en el diccionario desde la cuarta edición, se apunta, sin embargo, que está tomada del griego y, por otra parte, no 
se indica la procedencia etimológica latina de INTER. hasta que se incluye en la decimotercera edición y no cuando fue consignada anteriormente en la cuarta.

Una mayor sistematicidad en lo que se refiere a la utilización, en los correspondientes artículos lexicográficos del diccionario, de las abreviaturas que se incluyen en el listado de las páginas preliminares se observa a partir de la duodécima edición, si bien podemos citar algunas inadecuaciones, como el empleo, en esa misma edición, de alguna abreviatura (en concreto, part. inseparable) que no se cita ni explica en las páginas preliminares hasta la edición siguiente, o las de las entradas de las unidades $\mathbf{a}-{ }^{1}$. $y$ $\mathbf{a}^{2}{ }^{2}$. en la vigésima primera edición, la de 1992, que, tal vez por formar parte la caracterización de estas unidades de la expresión explicativa de la entrada, son catalogadas como prefijos (sic), sin usar la abreviatura correspondiente (pref.), a pesar de que ésta se viene empleando desde la decimoquinta edición, de 1925, y de que se recurre a ella para indicar la categoría gramatical de los otros prefijos de esa penúltima edición del diccionario académico.

Asimismo, respecto al señalamiento de la correspondencia latina, o griega, de las unidades que se consignan como entradas en el diccionario, se mantiene incluso en la undécima edición, a pesar de que en el «Prólogo» de ésta se nos advierte que dichas correspondencias latinas han sido suprimidas porque «tampoco podian servir de seguro guía para la etimologia de las voces castellanas, por cuanto el mayor número de éstas procede inmediatamente del latin vulgar, y las correspondencias se tomaban del latin clásico». No obstante, a partir de la duodécima edición del diccionario académico, la de 1884, y tal como se indica en las páginas de la parte introductoria que contienen la «Advertencia», se dan las etimologías de los vocablos españoles registrados en esta edición del diccionario. De ahí que, desde entonces, en todas las ediciones del diccionario usual de la Academia, con las únicas excepciones de las entradas de in- ${ }^{1}$. e in- ${ }^{2}$. en la edición de 1984, se indique entre paréntesis la etimología latina o griega de las unidades que son objeto de nuestro análisis.

Otra inadecuación entre los objetivos, modificaciones y propuestas de mejora que contienen las partes introductorias de los diccionarios y su plasmación en la elaboración de los artículos lexicográficos se observa en lo que respecta al sistema de referencias de unos artículos a otros, pues la primera mención sobre este aspecto no figura hasta la «Advertencia» de la decimocuarta edición del diccionario académico, la de 1914, en la que se nos indica que, en la última edición, «todas las acepciones de los artículos que tienen más de una, van numeradas según el orden que entre ellas se establece en cada artículo: con esto se facilitarán las frecuentes referencias de unos artículos a otros», y, sin embargo, para las unidades que son objeto de nuestro estudio, el sistema de referencias de unos artículos a otros se viene practicando desde la duodécima edición, de 1884, para Ad. y desde la decimotercera para Ad. y An., sin ninguna mención al respecto en los correspondientes apartados de «Advertencia» de estos diccionarios. Asimismo, en relación con este aspecto, hemos de anotar que en el «Preámbulo» de la decimonovena edición del diccionario usual de la Real Academia, la publicada en 1970, se nos indica que, aunque no se ha conseguido en su totalidad, se ha intentado suprimir las referencias numéricas a otras acepciones, «dando al lector la sola definición directa, entera o reducida de la acepción». Pero esto, al menos en lo que 
respecta a las dos unidades que hemos citado, no se cumple para ad. en las ediciones de 1970 y 1984 y tampoco para an-. ni en la edición de 1970 ni en ninguna de las posteriores, observándose además que, en el caso de este lema, se remite en la edición de 1970 al artículo de $\mathbf{a}^{3}{ }^{3}$., no existiendo ningún lema registrado como tal en esta edición del diccionario.

Una aplicabilidad más precisa se observa en lo que se refiere a la puesta en práctica del procedimiento que, en las correspondientes páginas preliminares de algunas ediciones del diccionario, se anuncia que se va a seguir para la separación de las acepciones en el interior del artículo lexicográfico. En efecto, el sistema de numeración de las distintas acepciones cuando hay más de una, empleado a partir de la decimocuarta edición, se suma al iniciado en la séptima, la del año 1832, consistente en separar mediante el símbolo de la doble barra vertical (\|) las acepciones de una misma voz, hasta entonces distinguidas, como se observa, por ejemplo, en el artículo del lema A., o bien repitiendo para cada acepción la grafía, a veces acentuada, de la entrada (cf. Real Academia Española, 1780, 1783, 1803, 1817 y 1822) o bien numerando las acepciones (cf. Real Academia Española, 1791). El sistema de separación de las acepciones mediante numeración y doble barra vertical se mantiene, al menos para las unidades que aquí estudiamos, con excepción de en la 9. ${ }^{a}$ edición del diccionario académico, la del año 1843, y con sólo variaciones en el formato del número, hasta la publicación de la vigésima primera edición del diccionario académico, la de 1992, en la que las acepciones de estos morfemas derivativos que eran distinguidas en ediciones anteriores del diccionario aparecen agrupadas en una misma acepción. Asimismo, en la versión electrónica de la última edición del diccionario académico (cf. Real Academia Española, 2003) tampoco se emplea el símbolo de la doble barra vertical, pero sí el sistema de numeración de las acepciones, incluso cuando sólo se registra una sola en el correspondiente artículo lexicográfico, a pesar de que en el apartado de «Advertencias para el uso de este Diccionario», al señalar la estructura que presentan los artículos del diccionario, se anuncia que se va a utilizar el mismo procedimiento que, con las excepciones señaladas, se venía empleando desde la séptima edición, esto es, el que consiste en que las acepciones correspondientes a un lema, cuando hay más de una, aparecerán numeradas y separadas por una doble barra vertical a partir de la segunda acepción.

Y para terminar este apartado, en el que hemos intentado, tal como anunciamos al principio, determinar si los objetivos que sobre las unidades que analizamos se exponen en las partes introductorias de los correspondientes diccionarios se cumplen realmente en el cuerpo del diccionario y la manera de llevar a la práctica tales objetivos en la confección del correspondiente artículo lexicográfico, nos parece oportuno señalar que, aunque entre las propuestas de mejora formuladas en las páginas preliminares de los diccionarios, que consisten, según se nos indica, esencialmente en el aumento del número de voces y acepciones; las enmiendas de artículos con la adición de nuevas acepciones y la actualización de las definiciones anticuadas, y la corrección de etimologías, no se hace mención alguna a los elementos que hoy en día se catalogan como prefijos, sino sólo a que dichas mejoras serán aplicadas a palabras, voces y locuciones, el análisis de la microestructura de las ediciones del diccionario académico nos permite comprobar que, aunque no se especifique, dichas modificaciones sí se aplican, como 
será visto en el siguiente apartado, también a las unidades trabadas que aquí estudiamos. No de otro modo se explicaría o justificaría la evolución en el tratamiento de éstas que se observa al contrastar las informaciones de los artículos lexicográficos de un mismo lema en las distintas ediciones del diccionario. Asimismo, nos interesa resaltar que entre las reformas que, dentro del plan de mejora, perfeccionamiento y actualización, se propone llevar a cabo progresivamente la Real Academia, se menciona, ya desde los prólogos de las ediciones quinta y sexta, esto es, las de los años 1817 y 1822 , la no incorporación y la supresión de, respectivamente, las voces fácilmente formables y la de aquéllas cuyo significado se comprende con facilidad a partir de su composición. Y parece obvio que la incorporación paulatina en el cuerpo del diccionario de las unidades que aquí estudiamos facilita esta tarea al hacer prescindible la presencia de muchas de esas otras voces que no se incluyen o se suprimen.

3. En relación con el segundo objetivo que nos planteamos cubrir en este artículo, esto es, determinar las analogías y, sobre todo, las diferencias que se observan al cotejar las informaciones que, sobre estas unidades morfológicas, se ofrecen en los diferentes repertorios lexicográficos y en las distintas ediciones de un mismo diccionario, fijaremos nuestra atención en los siguientes aspectos: en primer lugar, la manera en que aparece dispuesta la información semántica en los artículos lexicográficos de cada uno de los lemas consignados, sobre todo, si dicha información se recoge en una sola acepción, en acepciones distintas o en artículos lexicográficos de diferentes entradas de un mismo diccionario, asunto este que se encuentra intrincado con el del diferente tratamiento que, en las distintas ediciones o repertorios, se da a las que se consideran variantes formales de una misma unidad, tema este cuyo análisis vendrá a completar las observaciones que, sobre las referencias de unos artículos a otros en un mismo diccionario, expusimos en el apartado anterior. Y, por último, en relación con este mismo objetivo, nos ocuparemos de examinar las discrepancias en la caracterización lingüística o gramatical de las unidades morfológicas que estudiamos según los distintos repertorios lexicográficos o las ediciones diferentes de un mismo diccionario, lo que se relaciona con la diferente tipografía usada en el registro de los lemas de estas unidades.

Para abordar la primera de estas cuestiones, relativa a la información semántica contenida en los artículos lexicográficos, partiremos de la revisión de la consignada para los lemas $\mathbf{a}^{-}{ }^{1}$., $\mathbf{a}^{-}{ }^{2}$., an- ${ }^{1}$., an- ${ }^{2}$., in- ${ }^{1}$. e in ${ }^{-}$. en la versión electrónica de la última edición del diccionario usual de la Academia (cf. Real Academia Española, 2003) para cotejarla con la que figura en los correspondientes artículos lexicográficos de las anteriores ediciones del diccionario académico.

En efecto, desde el punto de vista de la información semántica, se observa que el contenido señalado para in ${ }^{1}$. aparece registrado en el diccionario académico desde la duodécima edición, mientras que el contenido semántico de in ${ }^{2}$. de la última edición del diccionario usual de la lengua española de la RAE se consigna en los diccionarios académicos desde la primera edición del mismo, habiéndose añadido a éste, en su misma acepción, el de in- ${ }^{1}$. en las ediciones duodécima, decimotercera y decimocuarta, y en una entrada distinta en la decimoquinta y siguientes, si bien sólo desde la decimo- 
novena, de 1970, las distintas entradas se distinguen con superíndice, aplicando la pauta lexicográfica, hoy en día habitual, de separar mediante una numeración distinta los lemas homónimos de orígenes etimológicos distintos. Ahora bien, si tal como se indica en las páginas introductorias de la última edición del diccionario académico, en concreto en el apartado de «Advertencias para el uso de este diccionario», «el orden de los artículos distinguidos por el superíndice depende de la mayor o menor antigüedad de su incorporación al Diccionario», está claro, desde la edición de 1970, que la entrada in- ${ }^{2}$. es la que debería aparecer como in- ${ }^{1}$. y ésta como in- ${ }^{2}$. Por su parte, respecto a las variantes formales de estas unidades (i-. e im-.), se explican los entornos fonológicos y ortográficos en los que éstas han de ser usadas en los artículos lexicográficos correspondientes a in- ${ }^{\mathbf{1}}$. e in- ${ }^{\mathbf{2}}$., si bien, además, en las ediciones vigésima primera y vigésima segunda estas variantes son también lemas distintos cuyos artículos contienen sólo el envío a los lemas in- ${ }^{\mathbf{1}}$. e in- $\mathbf{~}^{\mathbf{2}}$, lo que indica que la información que les corresponde se encuentra en los artículos correspondientes a estos lemas y que éstas son las variantes preferidas por la Academia porque llevan la definición directa.

Diferencias notables respecto al que ha arrojado el análisis de estas entradas presenta el cotejo de los artículos lexicográficos de los lemas $\mathbf{a -}^{\mathbf{1}} \cdot \mathrm{y} \mathrm{a-}^{\mathbf{2}}$. En efecto, el contenido semántico que se apunta para $\mathbf{a}^{2}$. en la vigésima segunda edición del diccionario académico aparece en el artículo lexicográfico de una entrada independiente del lema A. ya en la duodécima edición del diccionario usual de la Academia, la de 1884, mientras que la correspondiente información que contiene la edición actual en el artículo del lema $\mathbf{a}^{1}$., esto es, que «carece de significación precisa», al igual que la de la edición vigésima primera, puede ser considerada como una aclaración o especificación de la definición de carácter funcional gramatical que figura desde la edición decimocuarta hasta la vigésima, definición que, a juzgar también por los ejemplos que se incluyen, resulta de la conjunción de las indicaciones que se venían señalando para la entrada $\mathbf{A}$. desde la primera edición del diccionario académico, en algunos casos como acepciones distintas de la misma entrada (cf. Real Academia Española, 1780, 1783, 1791, 1803, $1817,1822,1832,1837,1843,1852$ y 1869$)$ y en otras en una entrada distinta (cf. Real Academia Española, 1884 y 1899, s. v. Á.). En este caso, frente a lo que denunciamos para in- ${ }^{\mathbf{1}}$. e in- ${ }^{\mathbf{2}}$, el orden de los artículos distinguidos por el superíndice para $\mathbf{a}^{\mathbf{1}} \cdot \mathrm{y} \mathrm{a-}^{\mathbf{2}}$. sí se corresponde con su mayor o menor antigüedad de incorporación al diccionario. Ahora bien, a diferencia también de los artículos de in- ${ }^{\mathbf{1}}$. e in- ${ }^{\mathbf{2}}$., excepto en las dos últimas ediciones del diccionario académico, no se cita en el correspondiente artículo lexicográfico la variante formal del lema $\mathbf{a}^{\mathbf{2}}$. (an- ${ }^{\mathbf{1}}$.) ni, por tanto, tampoco se menciona la explicación del entorno fonológico u ortográfico en el que ésta ha de ser usada, si bien, desde la decimotercera edición, de 1899, dicha variante es una entrada independiente del diccionario (cf. An.), de la que, además de la etimología, la categoría lingüística y un ejemplo, se especifica sólo el envío al correspondiente artículo del lema A. del diccionario.

Por su parte, an- $^{2}$. se registra como lema independiente en las ediciones vigésima primera y vigésima segunda, si bien el único mensaje contenido en el artículo es el envío al lema ana-., que está registrado desde la decimotercera edición, del año 1899 (cf. Ana.), aunque con menor información semántica que en las ediciones sucesivas, 
pues el contenido semántico señalado en esa primera edición se va ampliando sucesivamente hasta llegar a ser separado en cinco acepciones distintas en la última edición del diccionario. No obstante, en ninguna de las ediciones del diccionario, excepto en las vigésima primera y vigésima segunda, se incluye tampoco en el artículo del lema ana-. una mención a su variante formal.

$Y$ en lo que se refiere a la caracterización lingüística o gramatical que se señala para cada una de estas unidades en los correspondientes artículos lexicográficos, observamos que las unidades catalogadas como prefijos en las ediciones vigésima primera y vigésima segunda -si bien en la vigésima primera no se especifica ninguna información gramatical para las que son variantes formales de una unidad-, fueron consideradas anteriormente, cuando son registradas como tales unidades lexicográficas, como preposiciones $\left(\mathbf{a}^{1}{ }^{-}\right.$. in $^{2}{ }^{2}$.) en las ediciones primera, segunda y tercera; como preposiciones $\left(\mathbf{a}^{-}{ }^{1}\right.$. , in- ${ }^{2}$.), preposición inseparable (anti-.) y particula prepositiva (inter-.) en la cuarta edición; como preposiciones $\left(\mathbf{a}-{ }^{1}\right.$., in- ${ }^{2}$.) y preposición inseparable (anti-.) en la quinta edición; como letra del alfabeto $\left(\mathbf{a}^{-}{ }^{1}\right.$.), preposición inseparable (anti-.) y preposición $\left(\right.$ in $^{2}{ }^{2}$ ) en la sexta, séptima, octava, novena, décima y undécima edición; como letra del alfabeto y preposición que sirven de prefijo $\left(\mathbf{a}^{-1}{ }^{1}\right)$, particula inseparable $\left(\mathbf{a}^{2}{ }^{2}\right.$ ) y preposiciones inseparables (ad-., anti-., in- ${ }^{1}$., in- ${ }^{2}$.) en la duodécima edición; como preposición que sirve de prefijo y letra del alfabeto $\left(\mathbf{a}^{\mathbf{1}}{ }^{\mathbf{}}\right.$.), partículas inseparables $\left(\mathbf{a}^{-}{ }^{2}\right.$. , an- ${ }^{-}{ }^{-}$) y preposiciones inseparables (ad-., ana-., anti-.., in- ${ }^{1}$. , in- ${ }^{2}$., inter-.) en la decimotercera edición; como preposición que sirve de prefijo $\left(\mathbf{a}^{-}{ }^{1}\right.$.), partículas inseparables $\left(\mathbf{a}^{-}{ }^{2}\right.$., an- ${ }^{1}$.) y preposiciones inseparables (ad-., ana-., anti-., in- ${ }^{1}$., in- ${ }^{2}$., inter-.) en la decimocuarta edición; preposición que sirve de prefijo $\left(\mathbf{a}^{-}{ }^{-}\right.$), partículas inseparables $\left(\mathbf{a}^{-}{ }^{2}\right.$., an- ${ }^{-1}$.), preposiciones inseparables (ad-., ana-., anti-.., in- ${ }^{-}$., inter-.) y prefijo (in- ${ }^{2}$.) en la decimoquinta, decimosexta, decimoséptima y decimoctava, y como preposición que sirve de prefijo $\left(\mathbf{a}^{1}{ }^{1}\right)$, partículas inseparables $\left(\mathbf{a}^{2}{ }^{2} . \mathbf{a n}^{1}{ }^{1}\right)$, preposiciones inseparables (ad-., ana-., in- ${ }^{-}$, intra-.), prefijo $\left(\right.$in- $^{2}{ }^{2}$ ) y elementos compositivos (anti-., inter-.) en las ediciones decimonovena y vigésima. Ya que, aunque actualmente, tanto en la vigésima primera como en la vigésima segunda edición, se consideran prefijos, en las anteriores ediciones del diccionario, la unidad $\mathbf{a}^{-}{ }^{\mathbf{1}}$. ha sido catalogada también como preposición (en la 1. a $, 2 .^{\mathrm{a}}, 3 .^{\mathrm{a}}, 4 .^{\mathrm{a}}$ y 5 . $^{\mathrm{a}}$ ed.), letra del alfabeto (en la $6 .{ }^{\mathrm{a}}, 7 .^{\mathrm{a}}, 8{ }^{\mathrm{a}}, 9 .^{\mathrm{a}}, 10 .^{\mathrm{a}}, 11 .^{\mathrm{a}}$ y $13 .^{\mathrm{a}}$ ed.), letra del alfabeto que sirve de prefijo (en la $12{ }^{\mathrm{a}}$ ed.) y preposición que sirve de prefijo (en la $12 .^{\mathrm{a}}, 13 .^{\mathrm{a}}, 14{ }^{\mathrm{a}}, 15{ }^{\mathrm{a}}, 16{ }^{\mathrm{a}}, 17 .^{\mathrm{a}}, 18 .^{\mathrm{a}}, 19 .^{\mathrm{a}} \mathrm{y}$

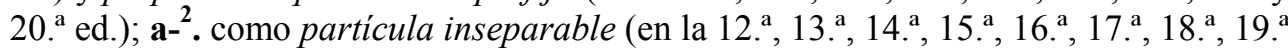
y $20 .^{\mathrm{a}}$ ed.); ad-. como preposición inseparable (en la $12 .^{\mathrm{a}}, 13 .^{\mathrm{a}}, 14 .^{\mathrm{a}}, 15 .{ }^{\mathrm{a}}, 16 .^{\mathrm{a}}, 17 .^{\mathrm{a}}$, $18 .^{\mathrm{a}}, 19 .^{\mathrm{a}}$ y $20{ }^{\mathrm{a}} \mathrm{ed}$.); an- ${ }^{1}$. como partícula inseparable (en la $13 .{ }^{\mathrm{a}}, 14 .{ }^{\mathrm{a}}, 15 .^{\mathrm{a}}, 16 .^{\mathrm{a}}, 17 .^{\mathrm{a}}$, $18 .^{\mathrm{a}}, 19 .^{\mathrm{a}}$ y $200^{\mathrm{a}}$ ed.); ana-. como preposición inseparable (en la 13. ${ }^{\mathrm{a}}, 14 .^{\mathrm{a}}, 15 .^{\mathrm{a}}, 16^{\mathrm{a}}$, 17. ${ }^{\mathrm{a}}, 18 .^{\mathrm{a}}, 19 .^{\mathrm{a}}$ y $20 .^{\mathrm{a}}$ ed.); anti-. como preposición inseparable (en la 4. ${ }^{\mathrm{a}}, 5 .^{\mathrm{a}}, 6^{\mathrm{a}},{ }^{\mathrm{a}}, \mathrm{.}^{\mathrm{a}}$, 8. ${ }^{\mathrm{a}}, 9 .^{\mathrm{a}} 10 .^{\mathrm{a}}, 11 .^{\mathrm{a}}, 12 .^{\mathrm{a}}, 13 .^{\mathrm{a}}, 14 .^{\mathrm{a}}, 15^{\mathrm{a}}, 16^{\mathrm{a}}, 17 .^{\mathrm{a}}$ y $18^{\mathrm{a}}$ ed.) y elemento compositivo (en la $19 .^{\mathrm{a}}$ y $20 .^{\mathrm{a}} \mathrm{ed}$.); in- ${ }^{1}$. como preposición inseparable (en la 12. ${ }^{\mathrm{a}}, 13 .^{\mathrm{a}}, 14{ }^{\mathrm{a}}, 15 .^{\mathrm{a}}, 16^{\mathrm{a}}$,

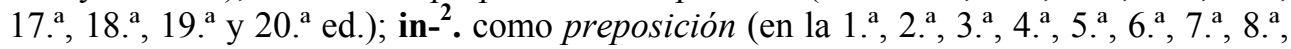
9. ${ }^{\mathrm{a}} 10 .^{\mathrm{a}}$ y $11 .^{\mathrm{a}}$ ed.), preposición inseparable (en la 12. ${ }^{\mathrm{a}}, 13 .^{\mathrm{a}}$ y $14 .^{\mathrm{a}}$ ed.) y prefijo (en la $15 .^{\mathrm{a}}, 16^{\mathrm{a}}, 17 .^{\mathrm{a}}, 18 .^{\mathrm{a}}, 19 .^{\mathrm{a}}$ y $20 .^{\mathrm{a}}$ ed.); inter-. como partícula prepositiva (en la $4 .^{\mathrm{a}} \mathrm{ed}$.), preposición inseparable (en la 13. $.^{\mathrm{a}}, 14 .^{\mathrm{a}}, 15 .^{\mathrm{a}}, 16 .^{\mathrm{a}}, 17 .^{\mathrm{a}}$ y $18 .^{\mathrm{a}}$ ) y elemento compositivo 
(en la 19. ${ }^{\mathrm{a}}$ y $20 .^{\mathrm{a}}$ ed.), e intra-. como preposición inseparable (en la 19..$^{\mathrm{a}}$ y 20. ${ }^{\mathrm{a}}$ ed.). Esta diferente caracterización gramatical de las unidades lexicográficas objeto de nuestro estudio tiene su reflejo también en la tipografía usada en las diferentes ediciones académicas para consignarlas como lemas. Así, mientras que en las dos últimas ediciones del diccionario académico, es sistemática la utilización del guión pospuesto en los lemas que son prefijos, los cuales, además, se presentan distinguidos con superíndices si son homónimos con distintos orígenes etimológicos, en la edición decimonovena se emplea el guión sólo para los lemas, ahora ya escritos en su totalidad con grafías minúsculas, ${ }^{3}$ que no aparecen distinguidos con superíndices y no pueden aparecer de modo independiente de las voces a las que se unen, esto es, que son inseparables — por tanto, los catalogados como partículas inseparables, elementos compositivos, preposiciones inseparables y prefijos-.

Pero, además de esta información relativa a la caracterización de las unidades lexicográficas, en los artículos confeccionados para algunas de ellas, se suelen incluir, aunque ya no en la decimocuarta edición, otras indicaciones gramaticales que versan sobre su utilización para la formación de otros vocablos, fundamentalmente en la composición, siendo, en el caso de las dos acepciones o entradas de A. que podrían hacerse corresponder con el prefijo registrado como a- ${ }^{\mathbf{1}}$. en la última edición del diccionario académico, el único contenido que, además de los ejemplos, se incluye en el artículo lexicográfico, mientras que para los lemas que se corresponden con los actualmente registrados como anti-. e in- ${ }^{2}$. esta definición funcional gramatical aparece unida a la que podríamos considerar la definición semántica propia de tales unidades morfológicas.

4. Y es precisamente en el análisis de estas informaciones gramaticales incluidas en los correspondientes artículos lexicográficos, las cuales versan, como decimos, sobre la caracterización lingüística de dichas unidades y su uso para la formación de otras voces, en el que nos basaremos para comprobar si, también respecto a estas unidades que estudiamos se produce el tantas veces mencionado hiato entre gramática y diccionario, es decir, si se atiende o no a las consideraciones teóricas que aparecen en las gramáticas a la hora de confeccionar los artículos lexicográficos de las unidades registradas en los diccionarios. En efecto, excepto en el artículo de la primera entrada de A. en la duodécima edición del diccionario académico, la de 1884, en el que se dice que puede servir de prefijo en vocablos como letra prostética o como derivación y en el de In. de las ediciones duodécima, decimotercera y decimocuarta, en el que se indica que es una preposición que puede denotar negación, inversión o contrariedad de la voz simple a la que aparece unida, en todos los demás casos se establece de manera precisa que las

${ }^{3}$ Ya que también se observan variaciones en la tipografía empleada para los lemas, pues desde la primera edición hasta la undécima inclusive y también en la decimoquinta se escriben enteros con mayúsculas y terminados en un punto y desde la edición duodécima hasta la decimoctava sólo con la inicial en mayúscula y el resto con minúsculas seguidas de un punto final. 
unidades lexicográficas citadas (las correspondientes a los lemas $\mathbf{a}^{\mathbf{1}}{ }^{\mathbf{}}$, anti-. e in- ${ }^{\mathbf{2}}$. en la 22. ${ }^{\mathrm{a}}$ ed.) sirven o se usan en la composición de vocablos. Y es el estudio de algunas de las ediciones de la gramática de la Real Academia Española el que nos permitirá comprobar si tales aseveraciones contenidas en los artículos lexicográficos de los diccionarios siguen o no los postulados expuestos en dichas gramáticas académicas.

En este sentido, se observa que ya en las primeras ediciones de la Gramática de la lengua castellana compuestas por la Real Academia Española (cf. Real Academia Española, 1771: 149, 1781: 31 y 1796: 41-42), se denominan compuestos a los nombres que se componen de dos o más palabras castellanas enteras o con alguna mutación, pudiendo estar constituidos, tales compuestos, entre otras estructuras, por la de preposición y nombre, como, en el caso de, por ejemplo, traspie. Resulta interesante completar estas afirmaciones con las que, también a propósito de los compuestos, se exponen a partir de la cuarta edición de la gramática académica (cf. Real Academia Española, 1796: 43), pues se distingue entre compuestos de preposiciones que sólo tienen significado en la composición, como, para citar ejemplos de compuestos con unidades consignadas en nuestro corpus, inmortal, impostura e interposición, y compuestos de preposiciones que tienen significado en la composición y fuera de ella, como, por ejemplo, abatanado. Por ello, se delimitan (cf. Real Academia Española, 1796: 247) dos especies de preposiciones: las que tienen significado en la composición de otras palabras y las que tienen significado en la composición de otras palabras y fuera de ella. E inferimos que la primera de las especies de preposiciones delimitadas engloba a las que son denominadas en los diccionarios preposiciones inseparables.

También contribuyen a clarificar las informaciones gramaticales contenidas en los artículos lexicográficos de las unidades que aquí estudiamos las definiciones de composición y de vocablo compuesto que aparecen en las ediciones de la Gramática de la lengua española publicadas en las primeras décadas del siglo XX, ya que se establece que «la composición reune dos o más palabras en una» (Real Academia Española, 1924: 142, 1928: 146 y 1931: 129) y, aunque también hay compuestos de preposición y relativo (porque, conque) y de preposiciones (desde), una de las clases de compuestos que pueden distinguirse es la de prefijo y adjetivo, verbo o sustantivo (inexpresivo, equidistar, archicofrade) (cf. Real Academia Española, 1924: 161, 1928: 165 y 1931: 147). En este sentido, se precisa que «los prefijos empleados en la composición y en la parasíntesis suelen ser preposiciones o voces que solamente como tales prefijos tienen en castellano uso y valor», citando entre éstos a $a$, an, $a d$, ana, anti, in e inter (cf. Real Academia Española, 1924: 165, 1928: 169-170 y 1931: 151). Por su parte, nos parece interesante resaltar que ahora se llama compuesto al vocablo «que consta de una palabra simple y de otra u otras voces o partículas ${ }^{4}$ como ante-coro, entre-fino, con-tener, a-donde» (Real Academia Española, 1924: 21, 1928: 23 y 1931: 21).

Por su parte, en el Esbozo de una nueva gramática de la lengua española (cf. Real Academia Española, 1973: 76), se hace referencia a los compuestos con prefijo, especi-

\footnotetext{
${ }^{4}$ La cursiva en este caso es nuestra.
} 
ficando que se incluye bajo el término prefijo «sobre todo preposiciones de origen latino o griego, pero también cualquiera otra forma de origen griego o latino, a condición de que tenga valor reproductivo en la composición española». Y se distingue entre prefijos que son separables, entre los que se incluyen la mayor parte de las preposiciones de origen latino, y prefijos que, preposiciones o no, son siempre inseparables, esto es, que no figuran nunca fuera de la composición.

Todo esto nos lleva a concluir que ni en las gramáticas ni, coherentemente, en los diccionarios académicos existe delimitación conceptual precisa para los términos preposición, preposición inseparable, prefijo, partícula y partícula inseparable, presentándose como equivalentes ${ }^{5}$ y siendo posible, por tanto, denominar indistintamente con estos términos a todas aquellas unidades que, antepuestas a otros vocablos simples, pueden intervenir en la formación de vocablos compuestos. En este sentido, de los términos que se utilizan en las ediciones académicas del diccionario usual de la lengua española para denominar a los elementos que en las últimas ediciones son llamados prefijos, sólo permanece inexplicable en las gramáticas académicas el término elemento compositivo que, en lo que respecta a las unidades lexicográficas que estudiamos, es utilizado, sin embargo, sólo para la caracterización gramatical de anti-. e inter-. en las ediciones decimonovena y vigésima.

5. Y, por último, procederemos a contrastar los resultados obtenidos del análisis de las unidades que nos ocupan que figuran registradas en las letras A e I de las ediciones del diccionario usual de la Real Academia con los que se obtienen de la revisión del tratamiento de estos mismos elementos de formación de palabras en muestras representativas de la lexicografía no académica.

En este sentido, parece oportuno precisar primero que el Diccionario de uso del español de M. Moliner (1966-1967), que vio la luz en el período comprendido entre las ediciones decimoctava y decimonovena del diccionario usual de la Academia, presenta unidas, como acepciones distintas pero en una misma entrada, las informaciones de artículos lexicográficos distinguidos como correspondientes a lemas homónimos diferentes desde la duodécima y decimoquinta edición del diccionario de la Real Academia, respectivamente (cf. Moliner, 1966-1967: s. v. a-., in-.), si bien, en otros artículos lexicográficos del $D U E$ (cf. 2an-.) se preludian, aunque en un mismo artículo y con la forma de remisión a otro, las que, en posteriores ediciones del diccionario académico, serían consignadas como entradas distintas y hasta entonces no tenidas en cuenta. Ahora bien, con independencia de estas cuestiones, y sin entrar en el estudio comparativo de la información semántica que se incluye en los artículos lexicográficos de las unidades registradas en las ediciones del diccionario de la Real Academia con respecto a la

${ }^{5}$ Hasta tal punto que, en los artículos lexicográficos correspondientes a in- ${ }^{2}$. de las ediciones decimoquinta a vigésima se indica que los cambios que sufre la $\mathbf{n}$ final son los mismos que la del prefijo anterior, esto es, el que se corresponde con in ${ }^{-}{ }^{1}$., que, sin embargo, en estas ediciones del diccionario es catalogado como preposición inseparable. 
que, para las mismas unidades, se ofrece en el $D U E$, resulta pertinente destacar los siguientes aspectos: 1) todas las unidades de nuestro corpus registradas en este Diccionario de uso del español son catalogadas como prefijos; 2) sólo para un prefijo (ana-.) se señala, aunque no con su alfabeto sino con caracteres latinos, su etimología entre paréntesis y sólo para otros tres (ad-., inter-. e intra. (sic)) se indica su procedencia o correspondencia latina; 3 ) en los correspondientes artículos lexicográficos, además de la información semántica, se incluyen las variantes ortográficas del lema y se explican los entornos en los que éstas han de ser usadas, si bien dichas variantes aparecen registradas también como lemas en el cuerpo del diccionario, aunque sólo con la especificación, mediante fórmulas distintas, de los entornos ortográficos en los que han de ser usadas, y 4) en los artículos lexicográficos de algunos prefijos (a-., anti-., in-.) se alude a sus posibilidades de intervención en la formación de otros vocablos y, para algunos de éstos (a-. in-.), se indican los matices significativos que aportan a la raíz a la que se afijan.

Las variaciones que, relativas a estos aspectos que conciernen a las unidades que estudiamos, se observan en la denominada segunda edición del DUE (cf. Moliner, 1998) radican, no tanto en las informaciones incluidas en los correspondientes artículos lexicográficos de los lemas que se consignan, pues éstas, salvo excepciones (ana-) o ligeras correcciones (i-), son las mismas, incluido algún que otro error de índole gramatical (im-), que las que figuran en el repertorio lexicográfico elaborado por María Moliner, sino en que, en la presentada como segunda edición del $D U E, 1)$ al igual que en las últimas ediciones del diccionario académico, se separan los artículos homónimos de orígenes etimológicos distintos $\left(\mathbf{a}^{\mathbf{1}}, \mathbf{a}^{-}{ }^{\mathbf{2}}, \mathbf{i n}-{ }^{\mathbf{1}}, \mathbf{i n -} \mathbf{-}^{\mathbf{2}}\right) ; 2$ ) sólo para estos artículos homónimos de orígenes etimológicos distintos, se especifica su distinta etimología entre paréntesis al principio del artículo, aunque siempre con caracteres latinos, y 3) se suprimen las entradas o lemas de algunas variantes formales, las cuales sí se incluían en la considerada edición original (así, por ejemplo, las entradas de intest-., intim-., intr-. como variantes de inter-.).

Por su parte, en el Clave. Diccionario de uso del español actual (cf. Maldonado González, dir., 2002) no se registran todos los lemas que figuran como prefijos en la última edición del diccionario académico, ${ }^{6}$ si bien, de los que se registran, se incluye, en los correspondientes artículos lexicográficos, 1) la mención de que se trata de prefijos; 2) la referencia de lo que tal prefijo indica o significa, aunque es notable la reducción del contenido semántico que se presenta en este diccionario en relación con el que se ofrece en prácticamente todas las ediciones del diccionario académico; 3) bajo los epígrafes de ORTOGRAFÍA, e incluso de MORFOLOGÍA, la cita de las variantes formales del lema y la explicación de los entornos en los que han de ser usadas, si bien tales variantes formales son también lemas del diccionario, con artículos en los que se remite a la variante principal y se explica también su uso, y 4) en último lugar, la etimología

${ }^{6}$ Así, no se incluyen ni acepciones ni entradas distintas que correspondan a los lemas a- ${ }^{1}$., ad., an $^{-2}$. e in- ${ }^{-}$. de la vigésima segunda edición del diccionario académico. 
latina o griega, aunque transcrita con caracteres latinos, de los prefijos registrados. Sin embargo, mayor es la reducción que, en lo que se refiere a lemas de prefijos que figuran en el cuerpo del diccionario, se observa en el Diccionario del español actual de M. Seco, O. Andrés y G. Ramos (1999), tal vez porque, como se menciona en el apartado preliminar destinado a fijar las «Características del diccionario», se pretende conceder entrada sólo a los prefijos que hoy son productivos en nuestro léxico ${ }^{7}$. Y, de los que se consignan, se anota en los correspondientes artículos lexicográficos, además de la información de contenido semántico y una abundante ejemplificación, el hecho de que son prefijos y, cuando procede, las variantes formales de los lemas con la explicación de los entornos en los que han de ser usadas, si bien dichas variantes no se incluyen como lemas del diccionario.

6. En este artículo, hemos analizado la evolución del tratamiento de los elementos de formación de palabras denominados actualmente prefijos en las distintas ediciones del diccionario usual de la lengua española que viene publicando la Real Academia desde $1780 \mathrm{y}$ en otros repertorios lexicográficos no académicos, y comprobado que las mayores discrepancias que se presentan en torno a las unidades morfológicas que analizamos radican, además de en la relación de las registradas en el correspondiente inventario lexicográfico, en la categoría lingüística o gramatical asignada a estas unidades; la utilización de abreviaturas para marcar esta categoría; la inclusión de la indicación de la correspondencia latina o griega o de la etimología del lema; la manera de disponer la información semántica en el cuerpo del diccionario; la forma de hacer referencia a las variantes formales de una misma unidad; el señalamiento de las remisiones de unos artículos a otros; el procedimiento utilizado para separar acepciones en un mismo artículo lexicográfico, y la distinta tipografía usada para registrar los lemas. Y estas diferencias se advierten, no sólo cuando se cotejan diferentes repertorios lexicográficos o distintas ediciones de un mismo diccionario, sino incluso en un mismo ejemplar al comparar los artículos lexicográficos de algunas de estas unidades con los de otras, hecho este que resulta aún más sorprendente si tenemos en cuenta el escaso número de las unidades catalogadas como prefijos en los diccionarios ${ }^{8}$ y los útiles informáticos con los que los lexicógrafos cuentan en la actualidad. Pero, en cualquier caso, parece que lo procedente ahora, de cara a las futuras ediciones del diccionario académico y a la publicación de otros repertorios lexicográficos, es determinar qué informaciones se deben ofrecer dentro de los artículos lexicográficos de los lemas que se consignen como prefijos en los correspondientes inventarios, $y$, desde nuestro punto de vista, para la toma de tal decisión, se han de tener en cuenta tanto las finalidades y características generales del diccionario como los propósitos que se pretendan conse-

\footnotetext{
${ }^{7}$ En este sentido, sólo se registran como entradas las de anti-, inter-, intra- e in- correspondiente a in- ${ }^{2}$. en las últimas ediciones del diccionario usual de la Academia. Academia.

${ }^{8}$ Así, por ejemplo, sólo se registran 52 prefijos en la última edición del diccionario usual de la
} 
guir con la inclusión, como artículos independientes, de estas unidades lexicográficas en la macroestructura del diccionario.

\section{APÉNDICE}

\section{RELACIÓN DE UNIDADES LEXICOGRÁFICAS ANALIZADAS}

- De los diccionarios usuales de la lengua castellana (1. a $14 .^{\mathrm{a}}$ ed.) y de la lengua española (15. a 22. ${ }^{\mathrm{a}}$ ed.) de la Real Academia Española:

(1780): A., IN.

(1783): A., IN.

(1791): A., IN.

(1803): A., ANTI., IN., INTER.

(1817): A., ANTI., IN.

(1822): A., ANTI., IN.

(1832): A., ANTI., IN.

(1837): A., ANTI., IN.

(1843): A., ANTI., IN.

(1852): A., ANTI., IN.

(1869): A., ANTI., IN.

(1884): A., Á., A., Ad., Anti., In.

(1899): A., Á., A., Ad., An., Ana., Anti., In., Ínter.

(1914): A., A., Ad., An., Ana., Anti., In., Ínter.

(1925): A., A., AD., AN., ANA., ANTI., IN., ÍNTER.

(1936 y 1939): A., A., Ad., An., Ana., Anti., In., Ínter.

(1947): A., A., Ad., An., Ana., Anti., In., Ínter.

(1956): A., A., Ad., An., Ana., Anti., In., Ínter.

(1970): $\mathbf{a}^{2}$., a-., ad., an-., ana ${ }^{2}$., anti-, in ${ }^{1}$., in ${ }^{2}$., inter-, intra-

(1984,): $\mathbf{a}^{2}$., a-., ad., an-., ana ${ }^{2}$., anti-., in- ${ }^{1}$., in- ${ }^{2}$., inter-., intra-.

(1992): a- ${ }^{1}$., a- ${ }^{2}$., ad-., an- ${ }^{1}{ }^{.}$, an- ${ }^{2}$., ana-., anti-., i-., im-., in- ${ }^{1}$., in- ${ }^{2}$., inter-., intra-.

(2003): a- ${ }^{1}$., $\mathbf{a}^{-}{ }^{2}$., ad-.., an- ${ }^{-}$., an- ${ }^{2}$., ana-., anti-., i-., im-., in- ${ }^{-}$., in- ${ }^{2}$., inter-., intra-. 
- Del Diccionario de uso del español (cf. Moliner, 1966-1967): a-., ad-., 2an-., ana-., anti-., 2i-., 1im-., in-., inter-., intra.

- De la denominada segunda edición del Diccionario de uso del español (cf. Moliner, 1998): $\mathbf{a -}^{\mathbf{1}}, \mathbf{a -}^{\mathbf{2}}$, ad-, an-, ana-, anti-, i-, im-, in- ${ }^{1}, \mathbf{i n}^{\mathbf{2}}$, inter-, intra-

- Del Clave. Diccionario de uso del español actual (cf. Maldonado González, dir., 2002): a-, an-, ana-, anti-, i-, im-, in-, inter-, intra-

- Del Diccionario del español actual (cf. Seco, Andrés y Ramos, 1999): anti-, inter-, intra-, in-

\section{REFERENCIAS BIBLIOGRÁFICAS}

Maldonado GOnZÁlez, Concepción, dir. (2002): Clave. Diccionario de uso del español actual, prólogo de Gabriel García Márquez, Madrid, Ediciones SM, 5. ${ }^{\mathrm{a}}$ ed., aumentada y actualizada.

MOLINER, María (1966-1967): Diccionario de uso del español, Madrid, Gredos, 2 vols. (1998): Diccionario de uso del español, Madrid, Gredos, 2. ${ }^{\text {e ed., }} 2$ vols.

REAL ACADEMIA ESPAÑOLA (1984 [1771]): Gramática de la lengua castellana (1771), edición facsímil y apéndice documental de R. Sarmiento, Madrid, Editora Nacional.

(1780): Diccionario de la lengua castellana compuesto por la Real Academia Española, reducido á un tomo para su mas fácil uso, Madrid, D. Joaquín Ibarra, 1. ${ }^{\text {ed. }}$

(1781): Gramática de la lengua castellana compuesta por la Real Academia Española, Madrid, D. Joaquín Ibarra, 3. a impresión.

(1783): Diccionario de la lengua castellana compuesto por la Real Academia Española, reducido á un tomo para su mas fácil uso, Madrid, D. Joaquín Ibarra, 2. ${ }^{\text {ed. }}$

(1791): Diccionario de la lengua castellana compuesto por la Real Academia Española, reducido á un tomo para su mas fácil uso, Madrid, Viuda de Don Joaquín Ibarra, $3^{\mathrm{a}}$ ed.

(1796): Gramática de la lengua castellana compuesta por la Real Academia Española, Madrid, Viuda de Don Joaquín Ibarra, 4. ${ }^{\mathrm{a}}$ ed. corregida y aumentada. 
(1803): Diccionario de la lengua castellana compuesto por la Real Academia Española, reducido á un tomo para su mas fácil uso, Madrid, Viuda de Don Joaquín Ibarra, $4 .^{\text {a }}$ ed.

(1817): Diccionario de la lengua castellana, Madrid, Imprenta Real, 5. ${ }^{\mathrm{a}} \mathrm{ed}$.

(1822): Diccionario de la lengua castellana, Madrid, Imprenta Nacional, 6. ${ }^{a}$ ed.

(1832): Diccionario de la lengua castellana, Madrid, Imprenta Real, 7. ${ }^{\mathrm{a}}$ ed.

(1837): Diccionario de la lengua castellana, Madrid, Imprenta Nacional, 8. ${ }^{a}$ ed.

- (1843): Diccionario de la lengua castellana, Madrid, Imprenta de D. Francisco María Fernández, 9. ${ }^{a}$ ed.

(1852): Diccionario de la lengua castellana, Madrid, Imprenta Nacional, 10. ${ }^{\mathrm{a}}$ ed.

(1869): Diccionario de la lengua castellana, Madrid, Imprenta de D. Manuel Rivadeneyra, 11. ${ }^{\mathrm{a}}$ ed.

(1884): Diccionario de la lengua castellana, Madrid, Imprenta de D. Gregorio Hernando, $12 .^{a}$ ed.

(1899): Diccionario de la lengua castellana, Madrid, Imprenta de los Sres. Hernando y Compañía, 13. ${ }^{\mathrm{a}}$ ed.

(1914): Diccionario de la lengua castellana, Madrid, Imprenta de los Sucesores de Hernando, 14. ${ }^{\mathrm{a}}$ ed.

(1924): Gramática de la lengua española, Madrid, Perlado, Páez y Compañía (Sucesores de Hernando), nueva edición, reformada.

(1925): Diccionario de la lengua española, Madrid, Espasa-Calpe, 15. a ed.

(1928): Gramática de la lengua española, Madrid, Librería y Casa Editorial Hernando, nueva edición, reformada.

(1931): Gramática de la lengua española, Madrid, Espasa-Calpe, nueva edición, reformada.

(1936): Diccionario de la lengua española, Madrid, Espasa-Calpe, 16. ${ }^{\mathrm{a}}$ ed.

(1939): Diccionario de la lengua española, Madrid, Espasa-Calpe, 16. ${ }^{\mathrm{a}} \mathrm{ed}$.

(1947): Diccionario de la lengua española, Madrid, Espasa-Calpe, 17. ${ }^{\text {a }}$ ed.

(1956): Diccionario de la lengua española, Madrid, Espasa-Calpe, 18. ${ }^{a}$ ed.

(1970): Diccionario de la lengua española, Madrid, Espasa-Calpe, 19. ${ }^{a}$ ed. 
(1973): Esbozo de una nueva gramática de la lengua española, Madrid, EspasaCalpe, 1982, 8. a reimpresión.

(1984): Diccionario de la lengua española, Madrid, Espasa-Calpe, 20. ${ }^{\text {ed }}$ ed, 2 vols.

(1992): Diccionario de la lengua española, Madrid, Espasa-Calpe, 21. . ed.

(2001): Nuevo tesoro lexicográfico de la lengua española, Madrid, Espasa-Calpe; edición electrónica.

(2003): Diccionario de la lengua española, Madrid, Espasa-Calpe; edición electrónica, 22. ${ }^{\text {a }}$ ed., segunda tirada corregida.

SECO, Manuel, dir., Olimpia de ANDRÉS y Gabino RAMOS (1999): Diccionario del español actual, Madrid, Aguilar, $3^{\text {a }}$ reimpr., 2 vols. 